\title{
1. Introduction: the role of agents and the establishment of the REDD+ regime
}

In view of urgent social and environmental problems, it is important to understand the political dynamics that may promote sustainable development and to identify the agents that make changes in this direction happen.

(Partzsch and Ziegler, 2011: 64)

\subsection{INTRODUCTION}

Forests cover 3.99 billion hectares, or 30.6 percent of the earth's total land area (FAO, 2015). Between 1990 and 2015, about 129 million hectares of forests were lost (FAO, 2015). Forests help in global biodiversity conservation; forest ecosystems represent 90 percent of terrestrial biodiversity (UNEP, 2002; World Bank, 2004). Forest loss leads to 100 species becoming extinct daily (Okereke and Dooley, 2010) and is a key global environmental problem.

Forest ecosystems have intrinsic, aesthetic, cultural, social and environmental values. Forests provide economic goods and services for humans, including fuelwood, construction materials, food, medicines, and wood and non-wood products (de Groot et al., 2002). Forests support the livelihoods of about 1 billion people, including 350 million poor people of whom 60 million are Indigenous Peoples for whom forests are part of their biocultural heritage (WCFSD, 1999; Sobrevila, 2008; FAO, 2010).

Forests store 289 gigatonnes of carbon, which is 86 percent of the earth's above-ground carbon, and stabilize the climate (de Groot et al., 2002; FAO, 2010). They help regulate local and regional hydrological flows and rainfall patterns (IPCC, 2002). Deforestation and forest degradation contribute between 12 and 17 percent of the anthropogenic greenhouse gas (GHG) emissions that cause climate change (Stern, 2006; Corbera et al., 2010; Siikamaki and Newbold, 2012; IPCC, 2014).

In light of their importance, governments agreed at the $1992 \mathrm{UN}$ Conference on Environment and Development (UNCED) that forests 
should be conserved and managed sustainably and that countries should "maintain existing forests through conservation and management, and sustain and expand areas under forest and tree cover" (Chapter 11 of Agenda 21, 1992). The 1992 UN Framework Convention on Climate Change (UNFCCC), which entered into force in 1994, includes a clear commitment to conserve and enhance forests and other carbon sinks and reservoirs.

The original idea for a specific regime to reduce emissions from deforestation and forest degradation, including conservation, sustainable forest management and enhancement of forest carbon stocks (REDD+), is assumed to come from a discussion paper published by Santilli in collaboration with certain Brazilian and US researchers (Santilli et al., 2005; Karsenty et al., 2012), although the concept of compensated reductions of deforestation had already been discussed at UNCED in 1992 (Humphreys, 2008; McDermott, 2014). In 2005, Papua New Guinea (PNG) and Costa Rica subsequently led in establishing a Coalition for Rainforest Nations (CfRN), which formally proposed a mechanism for reducing deforestation and forest degradation to the Conference of the Parties (COP) of the UNFCCC. In 2007, COP-13 initiated negotiations on this proposal, and after four years COP-16 decided that it:

Encourages developing country Parties to contribute to mitigation actions in the forest sector by undertaking the following activities, as deemed appropriate by each Party and in accordance with their respective capabilities and national circumstances:

(a) Reducing emissions from deforestation;

(b) Reducing emissions from forest degradation;

(c) Conservation of forest carbon stocks;

(d) Sustainable management of forests;

(e) Enhancement of forest carbon stocks.

Between 2007 and 2015 the REDD+ negotiations were marked by controversy. Social movements and some countries opposed REDD+ because of its underlying neoliberal roots. Nevertheless, the regime was finally agreed upon and included in the 2015 Paris Agreement to the UNFCCC.

The contemporary international forest regime consists of many separate yet partly overlapping commitments. When the UNFCCC started REDD+ negotiations, there were already more than 20 existing legally binding and non-legally binding international agreements that included commitments to conserve forests (see Appendix 4). Together these agreements form a multi-layered, complex international forest policy 
regime, which has been developed in an ad hoc manner at different speeds and in different directions (Humphreys, 2006; Gupta and Sanchez, 2012). There seems to have been limited institutional learning in the forest sector.

REDD+ is often presented as a significant opportunity for an environmentally effective, efficient and equitable forest conservation regime that will be able to succeed where other international forest regimes have failed, without proper comparative analysis of the environmental and social effectiveness, efficiency and equity of these existing regimes (e.g. Angelsen, 2008b; Putz and Zuidema, 2008; Skutsch et al., 2009; Streck et al., 2009a). As Alvarado and Wertz-Kanounnikoff (2008: 22) point out, "The current climate-driven debate on REDD+ should reflect on the reasons why previous efforts to combat deforestation and to reach an international forest agreement have had limited success (e.g. weak local-level institutions and governance structures, incoherent policies, political-economic interests etc.)."

So the question is: "Why did the UNFCCC parties decide, 15 years after its adoption, to elaborate the forest-related commitments in the Convention into a new international forest regime, given the other forest regimes adopted between 1992 and 2007?" This book addresses this question by analyzing the motivations and strategies of the main agents behind the REDD+ regime.

\subsection{REDD+ AND AGENCY THEORY}

An agent in international governance can be defined as an authoritative actor "who possesses the ability to prescribe behaviour and to obtain the consent of the governed" (Schroeder 2010: 320; see also Dellas et al., 2011). There is limited empirical research on the role of agents in specific environmental policy processes, and, as a relatively controversial regime that appears duplicative of existing regimes, REDD+ forms a useful subject to test the application of theories on the role of agents in international environmental governance. As Corbera and Schroeder (2011: 93) state, "more research efforts are required, particularly to understand what economic, socio-political and cultural factors determine effective participation, affect power relations and enable co-production of REDD+ strategies by governments, the private sector and civil society." They also identify the need "to examine which actors do not participate, whose views are side-lined and why. This issue, of course, overlaps with legitimacy questions, such as who is entitled to make decisions in the 
context of REDD+, and how such entitlement is constituted and respected by others" (Corbera and Schroeder, 2011: 93).

This book analyzes the agency and the motivations and strategies of different actors in the development of the REDD+ regime. It focuses on the question: "Which actors have been instrumental in shaping REDD+ policies and policy responses, what are their motivations and how do they use their agency to pursue their interests?"

Four criteria have been chosen to analyze the agency of State and non-State actors in REDD+ regime development, namely (1) legitimacy, (2) authority, (3) success in pursuing the original objectives and (4) assumed agency. Legitimacy and authority are closely related indicators of agency (Dellas et al., 2011). The core elements of legitimacy are the acceptance and justification of certain rules or institutions by the community as being authoritative. Legitimacy can be distinguished in terms of input legitimacy, which is related to responsibility, participation, accountability and transparency, and output legitimacy, which is determined by the results the actors produce (Backstrand and Lovbrand, 2006; Vatn and Vedeld, 2013). Legitimacy describes the state or quality of being coherent with established legal norms and requirements, recognized principles, or accepted rules and standards of behavior (Biermann and Gupta, 2011). Legitimacy is conferred through formal or informal social consent (Schroeder, 2010). Corbera and Schroeder (2011) argue that legitimacy can be based on the accountability of governments to their constituencies. This accountability is operationalized through public scrutiny, including of the processes through which rules and policies are negotiated, and the subsequent acceptance of decisions, which means they will be adhered to by these constituencies. They also highlight a fair distribution of decision-making power as a factor of legitimacy (Corbera and Schroeder, 2011).

Normally, the legitimacy of a State is uncontested, although in specific cases the legitimacy of specific representatives of a State could be contested (see also Chapter 7). According to the assumption of formal democracies, people, who can be seen as principals, elect their government and are subsequently represented by it. The government thus functions as an agent that legitimately acts on behalf of the people, is accountable to them, and can be voted out in cases of dissatisfaction (Partzsch and Ziegler, 2011). Thus representativeness and accountability are important indicators of legitimacy. Governments subsequently negotiate international agreements, which are normally adopted based on consensus.

The legitimacy of non-State actors is not a given (Dellas et al., 2011), especially because their representativeness is not a given. Rather, it is 
seen as a determining factor in their agency. Non-State actors are not elected through a formal democratic process, so their agency is mostly justified by other factors (Dellas et al., 2011). Partzsch and Ziegler (2011) identify utility, embeddedness and education as potential sources of legitimacy of non-State actors. They also identify the role of certain agents as advocates for more transparency and the empowerment of affected people as a potential source of legitimacy. Thus legitimacy is a relative concept - legitimacy is in the eye of the beholder (Biermann and Gupta, 2011; see also Dellas et al., 2011). Having said that, representativeness is also an important indicator of the legitimacy of non-State actors.

Legitimacy is closely linked to accountability, which requires transparency of governance processes and outcomes. Global environmental governance creates a challenge of securing accountability, because traditional accountability mechanisms like electoral accountability and legal representation are not applicable to global environmental governance, including even State-led governance. Biermann and Gupta (2011) further distinguish internal accountability and external accountability. In the latter case, the actors whose lives are impacted by certain decisions are not directly linked to the actors that should be held to account for those decisions. This is of particular relevance to global environmental governance. The effects of transboundary environmental harm caused by failing national governance reach beyond national borders, but the affected actors have no electoral means to hold these failing decision-makers accountable (Biermann and Gupta, 2011). Biermann and Gupta (2011) also identify temporal interdependence in terms of an accountability challenge relating to future generations, and accountability relations between past and present generations.

Authority, the second indicator of agency chosen, is defined as "the legitimacy and capacity to exercise power" (Schroeder, 2010: 320). Especially in the case of non-State actors, their authority is often contested, and the recognition of their authority as innovative problemsolvers is an important factor in their agency (Dellas et al., 2011). As discussed in section 2.6, the shift from government to governance assumes new spheres of authority beyond States, which are based on persuasion rather than coercion (Pattberg, 2005; Dingwerth and Pattberg, 2006; Arts, 2012). For that reason, authority is a relative concept and much related to the assumed expertise, influence and moral authority of the actor and social interactions. It is a quality actors acquire rather than possess (Biermann et al., 2009a). Bouteligier (2011) distinguishes five different types of authority: institutional authority, delegated authority, expert authority, principled authority and capacity-based authority. 
Partzsch and Ziegler (2011) argue that the definition that "an agent of Earth System Governance is an actor who possesses the ability to prescribe behaviour and to obtain the consent of the governed" (Schroeder 2010: 320) implies that such an actor obtains the authority on behalf of others. This means that we need to investigate the legitimizing reasons that turn this exercise of power into authority (Partzsch and Ziegler, 2011), since States cannot simply transfer their democratic legitimacy to non-State actors. However, Partzsch and Ziegler also identify innovations as a potential source of authority, for example in the case of social entrepreneurs as agents in environmental governance (Partzsch and Ziegler, 2011).

Expertise, which underlies authority, is subjective, and is directly related to the epistemology and knowledge of the actors that judge another actor's expertise (Stewart-Harawira, 2005). There is a (neo-)colonial dimension to the concept of expertise, as Indigenous and other non-Western forms of expertise are often less appreciated by scientists with a Western background, and even scientists with a non-Western background (Apgar et al., 2015). For that reason, the main indicator chosen is whether the expertise and/or authority of a certain actor was questioned by co-actors, taking into account the background of the judging actors themselves.

The third and fourth indicators that will be used concern the assumption of agency of an actor in the eyes of co-actors and the effectiveness of agency as indicated by the capacity of an actor to influence the process according to the original goals and objectives of that actor (see also Dellas et al., 2011). The assumption of agency has been tested through short, open interviews, in which key actors in the REDD+ regime have been asked who, or which organization, they would consider the main agent behind the REDD+ regime, independent of their authority and legitimacy.

The capacity of an actor in reaching his/her original objectives through the final regime is an important indicator of the influence a particular actor has had on the regime. As an indicator of the objectives of the different agents, the position of the different agents regarding REDD+ will be analyzed and compared with the final REDD+ regime as it was incorporated in the 2015 Paris Agreement.

This book also aims to contribute to a growing body of analysis on the role and motivations of agents in international environmental governance in general by applying existing theories about regime development and the role of agents in international environmental governance, which will be further elaborated in Chapter 2 (e.g. Haggard and Simmons, 1987; Young, 1991; Hasenclever et al., 1997; Pattberg, 2005; Biermann, 2007; 
Smouts, 2008; Dellas et al., 2011; Underdal, 2011; Weible et al., 2012), to REDD+. By analyzing the motivations and strategies of these actors, this study also tests the relevance of the most important regime-building theories for a concrete international environmental regime like REDD+. These regime-building theories include (a) power-based theories, which are based on the assumption that the function of a regime is to distribute the costs and benefits associated with cooperation in a manner that is convenient to the most dominant player, (b) interest-based theories, which reflect an assumption of rational choice by all the agents involved leading to a regime that reflects the interests of all, and (c) knowledgebased theories, which are based on the assumption that agents will act according to a logic of appropriateness (Hasenclever et al., 1997). Thus it will be analyzed whether economic or other forms of coercion rather than consent have shaped agency in the REDD+ regime (Dellas et al., 2011).

The book also addresses the interactions between agents and the role of discourse, policy entrepreneurs and coalition-building in regime development. The links between the motivations and strategies of different agents are analyzed, to what extent the assumed beneficiaries of REDD+ were able to play a role in the design and implementation of the REDD+ regime, and what the implications can be of unbalanced participation of stakeholders and rightsholders in regime development. Thus the book aims to contribute to the question: "Who ultimately governs the earth system?" (Dellas et al., 2011: 90). To that end, use will be made of legal and empirical data drawn from the REDD+ regime, including the views of potential agents themselves and other actors in the REDD+ negotiations.

The book aims to contribute to the international search for coherent, environmentally effective, economically efficient and socially equitable policies to address deforestation and forest degradation. It also provides some suggestions for more balanced participation of the assumed beneficiaries of REDD+ in international forest policy design and implementation. It goes beyond existing forest policy analysis by analyzing the extent to which the flaws and dilemmas in the current REDD+ regime are a result of the economic and political interests and/or ideologies of the actors that advocated for this regime. By analyzing which agents have advocated REDD+ and why, this study aims to contribute to a better understanding of the likely impact REDD+ will have in terms of the effectiveness, efficiency and equity of global forest policy. A focus on environmental effectiveness, economic efficiency and social equity has been chosen to reflect the three main pillars of sustainable development, the environmental, economic and social pillars (Rayner et al., 2010). 
The role of prominent REDD+ donors like the Government of Norway and organizations like the World Bank receive particular attention (see sections $7.4,8.5$ ). The research also addresses the role of REDD+ countries, in particular the CfRN, which has been the lead actor promoting REDD+ in the climate negotiations (Chapter 3). Moreover, specific attention is paid to the role and interests of non-governmental actors, including large conservation organizations, in promoting REDD+ and their role and interests as REDD+ intermediaries (Chapter 4).

This first chapter will continue to describe how the REDD+ regime was established and incorporated in the 2015 Paris Agreement. It will discuss the incorporation of forests in the UNFCCC and its Kyoto Protocol (section 1.3), the development of the REDD+ regime between 2002 and 2007 (section 1.4), the early years of REDD+ (section 1.5), and how REDD+ was further developed on the road to Paris (section 1.6). It will end with some analysis about the current state of REDD+ post-Paris.

\subsection{THE INCORPORATION OF FORESTS IN THE UNFCCC AND ITS KYOTO PROTOCOL}

Contrary to what has sometimes been claimed (Alvarado and WertzKanounnikoff, 2008; Cerbu et al., 2011; Srivastava, 2011), forests have been an integral part of the UNFCCC regime from the start. Countries were urged to reduce the loss of forests and other carbon sinks through UNFCCC Article 4.1.d, and developing countries could apply to the financial mechanism of the UNFCCC, the Global Environment Facility (GEF), for financial support to do so (McDermott et al., 2010). In 1995, UNFCCC COP-1 decided to initiate negotiations on a protocol to the Convention that would include quantified legally binding emission reduction commitments for the countries that contributed most to the global warming problem (Bausch and Mehling, 2006). These negotiations included an agenda item on so-called land use, land-use change and forestry (LULUCF). Interviewees have pointed out that the agreement to include LULUCF was central to the adoption of the Kyoto Protocol, as the US, which participated in these negotiations until the end, could not agree to a 7 percent reduction of GHG emissions if it could not include reductions from its LULUCF sector, which it estimated as representing at least half its overall target (Hoehne et al., 2007; see also Fry, 2011; interview 43, June 2013). Hence, the Kyoto Protocol agreed to include the sector, through a process that was "typified by confusion, manipulated science, obfuscation and poor decision making" (Fry, 2002: 159). 
There was no time prior to 1997 to negotiate all the technical rules and modalities regarding LULUCF, so the parties to the UNFCCC requested the Intergovernmental Panel on Climate Change (IPCC) to elaborate a special report on this matter. The report, a combination of scientific and legal analyses, was published in 1999 and formed the basis for two years of complex and highly polarized negotiations (Fry, 2011). The EU expressed concerns about the methodological complications related to the inclusion of forest conservation in the Kyoto Protocol, but countries like Japan and Norway took over the role of LULUCF champions after the US publicly announced its intention in 2001 not to join the Protocol. Japan especially was interested in LULUCF, as its energy sector was relatively efficient, so it was not able to commit to significant reductions in that sector (interview 43, June 2013; interview 45, June 2013). Meanwhile, EU countries became gradually more in favor of using LULUCF credits (Fry, 2011).

The LULUCF negotiations were so polarized that many see them as the main cause of the collapse of the negotiations at UNFCCC COP-6 in 2000 in The Hague (Fry, 2002; Karsenty, 2008; Palm et al., 2008), although uncertainty about the political situation in the US at the time of the conference also played a role in the tensions. The chair of the COP, then minister Jan Pronk of the Netherlands, tried to save the situation by proposing the option that avoiding deforestation and combating land degradation would be recognized as actions that could be funded through the Adaptation Fund, but no agreement was reached on this proposal at the time (Fry, 2002; Karsenty, 2008). The resumed COP in 2001 in Bonn reached political agreement on at least some of the LULUCF-related questions. The subsequent withdrawal of the US from the Kyoto Protocol implied a significantly increased negotiating power for Japan and other pro-LULUCF countries, as the survival of the Protocol now depended on their willingness to ratify the instrument (Fry, 2002; Bausch and Mehling, 2006). Moreover, all parties realized that another round of failed negotiations would bring the entire future of the Kyoto Protocol into jeopardy (Boyd and Schipper, 2002). At COP-7 in December 2001 in Marrakesh, which was marked by a non-transparent and confused negotiation process, an agreement on almost the entire package of rules regarding LULUCF was reached (Boyd and Schipper, 2002; Levin et al., 2008; Palm et al., 2008). The environmental integrity of these accords, which partly depend on the good faith of the parties as far as properly accounting for land-use-related emissions is concerned, is questionable (Boyd and Schipper, 2002; Fry, 2002; Jacquemont and Caparros, 2002).

For those countries adopting legally binding quantified emission reduction commitments, the Marrakesh Accords allowed the inclusion of 
reforestation and afforestation as well as forest conservation and a range of other forest-related activities in the emission calculations. However, an exception was made regarding the possibility of using forest conservation projects in the newly established Clean Development Mechanism (CDM) (Fry, 2008; Levin et al., 2008). The CDM is at the heart of the so-called "cap-and-trade" regime established by the Kyoto Protocol, through which the industrialized countries included in Annex 1 of the Protocol take up legally binding quantified emission level reduction obligations, but are allowed to use so-called "flexible mechanisms" to reach them. These mechanisms include emissions trading through carbon markets, joint implementation and the CDM (Wettestad, 2009). The idea behind this scheme is that it would provide a strong economic incentive to look for the most low-cost and efficient initiatives to reduce GHGs (Grubb et al., 2011). Through the CDM, Annex 1 countries are allowed to buy carbon offsets produced through emission reductions in developing countries, which can be counted as meeting part of their own emission reductions. ${ }^{1}$ The CDM is considered to represent the largest segment of the flexible mechanisms and as such it was initially highly successful. In the first year after it started registering projects in November 2004 around 1965 projects were registered (Wettestad, 2009).

The formal reasons why forest conservation projects were excluded from the CDM were related to the technical aspects that are further elaborated in Chapter 6: the risks of leakage and non-permanence and the difficulties of properly calculating the impact of the LULUCF sector on emissions (Karsenty, 2012; Stephan and Paterson, 2012) or establishing a reference level against which to calculate emission reductions. However, some interviewees as well as scholars have pointed out that the huge potential of the LULUCF sector, and the subsequent risk that the global carbon market would be flooded with forest conservation credits, was perhaps the main underlying reason for exclusion, especially for the EU, Brazil and the Alliance of Small Island States (AOSIS) (Streck et al., 2009b; Dutschke, 2010; McDermott et al., 2010; Fry, 2011; interview 43, June 2013; interview 45, June 2013). They feared that oversupply of credits would lead to a dramatic drop in the carbon price, while a high price was considered essential to ensure a strong economic incentive for emission reductions in other sectors. As the emission targets for Annex 1 countries had already been agreed upon prior to 2001, the inclusion of avoided deforestation in the CDM in Marrakesh would not have contributed to additional reductions (Bond et al., 2009). The potential of the LULUCF sector also formed an important reason not to include entire sectors but only specific activities in the flexible mechanisms (interview 
43, June 2013). An additional concern was related to sharing the burden and responsibility for historical GHG emissions (Stephan and Paterson, 2012).

Countries like Costa Rica, whose main potential for emission reductions was forest conservation, were disappointed that forest conservation was excluded from the CDM (Boyd et al., 2008; interview 3, December 2011; interview 24, September 2012; interview 40, December 2012). While this position was shared by some of the large conservation NGOs (see section 4.3), many other NGOs opposed sinks in the CDM owing to concerns about the potential environmental and social impacts of using a vulnerable ecosystem upon which some of the most economically marginalized groups in society depended as an offset for industrial emissions (Graichen, 2005; McDermott et al., 2010). For them, the inclusion of reforestation and afforestation projects in the CDM was the worst of possible scenarios (Boyd, 2009), because among other factors there is no clear standard for sustainable development in the CDM (Gupta, 2008) and the contribution of reforestation and afforestation projects to sustainable development is considered questionable (Olsen, 2007).

To address the problem of permanence (see subsection 6.2.3), it was decided to create a special class of temporary carbon credits for LULUCF-related CDM projects. Such temporary credits ${ }^{2}$ only postpone the obligation to reduce emissions; they do not fulfil them. After a certain period, they will have to be replaced by permanent credits, which means that they are relatively unattractive for carbon brokers (Stephan and Paterson, 2012). Moreover, it was decided that industrialized countries are not allowed to offset more than 1 percent of their emissions (using a 1990 baseline) through afforestation and reforestation projects (Bozmoski and Hepburn, 2009; Streck et al., 2009b). ${ }^{3}$ As a result, reforestation and afforestation projects never became popular. By 2012 they constituted only 0.7 percent of the total volume of certified emission reductions issued for all CDM projects (Gupta and Sanchez, 2012).

COP-9 and COP-10 in 2003 and 2004 respectively continued to further refine the rules and modalities for LULUCF projects in general, making it easier for small-scale CDM LULUCF projects to be approved. However, they did not readdress the issue of financing forest conservation projects (Bausch and Mehling, 2006; Boyd et al., 2008; Palm et al., 2008). The Marrakesh Accords were adopted at the first Meeting of the Parties (MOP) to the Kyoto Protocol in 2005, a conference that was marked by disappointment about stricter conditionalities being imposed on funding through the GEF, the official financial mechanism of the 
UNFCCC (Schipper and Boyd, 2006). Carbon sinks received an additional blow by the so-called Linking Directive of the EU, which was adopted in $2005 .{ }^{4}$ In this Directive, the EU decided to exclude all LULUCF projects, including reforestation and afforestation projects, from its internal Emissions Trading Scheme, owing to concerns about the temporary nature of the credits and the potential environmental impacts of invasive alien species and genetically modified trees that might be used in reforestation and afforestation projects (Graichen, 2005; Bozmoski and Hepburn, 2009; Streck et al., 2009b). Thus fertile ground was created for the sentiment that forests should be excluded from the CDM, or even the sentiment that forests should be excluded from the climate regime in general (Schipper and Boyd, 2006; Wertz-Kanounnikoff, 2007; Alvarado and Wertz-Kanounnikoff, 2008; Basnet, 2009; McDermott et al., 2010; Cerbu et al., 2011; interview 40, December 2012).

\subsection{THE DEVELOPMENT OF THE REDD+ REGIME}

The concept of "compensated reductions" had already been discussed by various scholars, including in a well-known article by Santilli et al. (2005). Several scholars and policymakers see this article as the starting point of REDD+ (Skutsch et al., 2007; Karsenty et al., 2012; interview 24, September 2012; interview 25, September 2012), although others have pointed out that the LULUCF agreement in 1997 had already laid the foundations for REDD,$+{ }^{5}$ and REDD+-like proposals featured in earlier literature (e.g. Andersson and Richards, 2001). In fact, the idea of financial compensation for reducing deforestation had already been proposed and widely debated at UNCED 1992.

The proposal for a regime to reduce emissions from deforestation was further promoted by NGOs at the UNFCCC COP in 2004 (Allan and Dauvergne, 2013). At a Seminar of Government Experts on the future of the climate regime organized by the UNFCCC in June 2005 PNG proposed including avoided deforestation in international carbon markets (Fry, 2007). Subsequently, the proposal for compensated reductions was formally introduced in the UNFCCC negotiations by PNG and Costa Rica on behalf of the then eight members of the newly formed Coalition for Rainforest Nations at COP-11 in Montreal (Fry, 2007; Sasaki and Putz, 2009; Cashore et al., 2010; interview 9, March 2012; interview 45, June 2013).

The original proposal by the CfRN also asked for reopening the Marrakesh Accords to allow for the inclusion of avoided deforestation in the CDM (Fry, 2007; Angelsen, 2008b). Brazil, on behalf of the G-77 
and China, subsequently succeeded in convincing other countries to continue discussions on reducing deforestation under the Convention itself, which meant that the discussion no longer addressed a possible renegotiation of the Marrakesh Accords of the Kyoto Protocol (Schipper and Boyd, 2006; Fry, 2007; Angelsen, 2008a). Countries like Costa Rica decided to accept this option, as they realized it was the only feasible compromise (interview 40, December 2012). Parties also decided to continue discussions under the Subsidiary Body on Scientific and Technical Advice (SBSTA) rather than the Subsidiary Body on Implementation (SBI), which meant that the discussion would initially deal with relatively less controversial methodological issues and not with the trickier issue of finance (Schipper and Boyd, 2006; Fry, 2007; WertzKanounnikoff, 2007). Thus the revised proposal received remarkably broad support (Schipper and Boyd, 2006; Allan and Dauvergne, 2013; interview 1, October 2011).

The timing of the introduction of a regime for reducing deforestation benefited from the fact that the Montreal COP-11 was marked by a sphere of optimism and collaboration following the adoption of the Marrakesh Accords, which gave countries the feeling that the main controversies around LULUCF were solved (interview 11, March 2012; interview 45, June 2013). Many people considered the proposed new forest regime as a win-win solution both for tropical forest countries themselves and for industrialized countries. Tropical forest countries and several NGOs saw it as a significant potential funding source for the forestry sector at a time when forestry funding had been declining some even saw it as "a pot of gold at the end of the rainbow" (Fry, 2007: 355; see also Angelsen, 2008b; interview 38, December 2012). It has also been suggested that industrialized countries saw it as an "ideal option" to avoid changing lifestyles, energy systems or industrial production processes (Allan and Dauvergne, 2013: 1314) and business as usual in general (interview 33, December 2012; interview 57, December 2013). Other academics argued that low-cost offsets would allow industrialized countries to take on higher reduction commitments (Stephan and Paterson, 2012). Another political tendency that worked in favor of the new regime was the gradual acceptance by an increasing number of countries of the idea that developing countries would have to contribute to climate change mitigation too, despite the principle of common but differentiated responsibilities (CBDR) (Kulovesi and Gutierrez, 2009; interview 45, June 2013; interview 54, November 2013). Meanwhile, even the more critical NGOs and social movements that had been campaigning passionately against the inclusion of avoided deforestation in the CDM were not squarely opposed to the proposal to reduce emissions from deforestation 
(RED) when it was originally introduced, because it was considered an improvement as compared to the original proposal to compensate for "avoided deforestation," which raised a number of questions regarding baselines and additionality (see subsection 6.3.2). Rather, most of them focused their opposition on the option that such reductions might be financed through carbon offsets. ${ }^{6}$ It was not until the 2010 World People's Conference on Climate Change and the Rights of Mother Earth in Cochabamba, Bolivia, ${ }^{7}$ that the majority of social movements and social justice NGOs, and the Bolivian government itself, started to take a principled stand opposing all forms of REDD+ as a forest policy that was inherently based on a neoliberal, market-based conservation ideology.

At the subsequent meeting of the SBSTA in 2006, Brazil formally introduced a proposal to compensate reduced emissions from deforestation through a fund rather than carbon markets (Schipper and Boyd, 2006; Fry, 2007). These proposals were further elaborated at a UNFCCC workshop in Rome, Italy, in August 2006 and a workshop in Cairns, Australia, in March 2007 (Fry, 2007; Dutschke, 2010). The proposal for compensated reductions received further impetus from the fourth assessment report of the IPCC (IPCC, 2007) and the influential report of the Stern Commission on the Economics of Climate Change (Stern, 2006). ${ }^{8}$ The latter report strongly supported reducing deforestation as a relatively inexpensive climate change mitigation policy with multiple benefits (Spence et al., 2008; Skutsch and McCall, 2010; interview 8, December 2011; interview 9, March 2012). The Stern report also alerted the private sector to the potential business opportunities of an avoided deforestation mechanism. ${ }^{9}$ At the UN Summit on Climate Change organized by UN secretary-general Ban Ki-moon in September 2007, the secretary-general personally highlighted the need to address emissions from deforestation (Aguilar, 2007; Spence et al., 2008). A similar conclusion was reached by the Major Economies Meeting on Energy Security and Climate Change, which was convened in the same month by the US (Aguilar, 2007; Fry, 2007).

The organization of the first Forest Day by the Indonesian-based Center for International Forestry Research (CIFOR) parallel to the Bali conference is seen to have played an important role in creating support for the RED proposal (Wertz-Kanounnikoff, 2007; interview 3, December 2011; interview 4, December 2011). The proposal was included in, and further elaborated as part of, the overall negotiations on what became known as the Bali Action Plan, the two-track negotiation process COP-13 adopted in 2007 to reach and elaborate a successor agreement to the Kyoto Protocol and what was called a "framework for long-term cooperative action" (Fry, 2008; Humphreys, 2008; Spence et al., 2008; 
Kulovesi and Gutierrez, 2009). It formed the start of an intense two years of negotiations. The Bali Action Plan included a mandate to further elaborate a mechanism that would provide policy approaches and positive incentives for forest conservation, and for the sustainable management of forests and forest restoration. ${ }^{10}$

The proposed new regime was called REDD+ to express the fact that it would cover the reduction of emissions from deforestation and forest degradation and promote conservation, sustainable forest management and enhancement of forest carbon stocks. The fact that the mechanism would address not only deforestation but also forest degradation, conservation, sustainable management and enhancement of forest carbon stocks was the result of a compromise between the original proponents of REDD+, countries like PNG and Brazil that faced high deforestation rates, and countries like India and the Central African countries, which had relatively low deforestation rates and thus little to gain from a mechanism that would provide results-based payments for reducing deforestation only (Dutschke and Wertz-Kanounnikoff, 2008; Allan and Dauvergne, 2013; interview 9, March 2012; interview 40, December 2012). The expanded scope also increased the number of potential beneficiaries (Allan and Dauvergne, 2013) and thus the number of countries supporting REDD+. Moreover, the Bali Action Plan included an element that supported the possibility for REDD+ to be considered in adaptation policies (Fry, 2008).

\subsection{THE EARLY YEARS OF REDD+}

Some interviewees pointed out that the contents of the Bali decision were rather simplistic from a forest sector point of view, which was partly due to the fact that relatively few forestry sector specialists were involved in the UNFCCC negotiations at that time (interview 8, December 2011; interview 9, March 2012; interview 33, December 2012). They suggested that many climate policymakers assumed that reducing deforestation was something that was easy to implement (interview 33, December 2012). Negotiators realized that there were still quite a few issues to be resolved, though, so the Bali Action Plan was complemented by a specific decision $^{11}$ that identified a whole range of methodological issues that still had to be resolved by the SBSTA. These included assessments of changes in forest cover and the effectiveness of actions, demonstration of reduction in emissions from forest degradation, proper establishment of reference levels for estimating reduced emissions, and the potential implications of displacement of emissions, especially when actions were 
to be financed through carbon offsets (Streck et al., 2009b; see also Chapter 4).

Despite these methodological questions to be resolved, the decision also encouraged parties to undertake demonstration activities and other efforts to address the drivers of deforestation immediately, and suggested that the results of these activities might be taken into account in future payments (Levin et al., 2008). The decision also invited industrialized countries to provide support to such demonstration activities. These demonstration actions and REDD+ in general subsequently received a significant boost by the announcement of the Government of Norway at COP-13 in Bali in 2007 that it would provide a total of 3 billion Norwegian krone per year over a period of five years (USD 2.7 billion in total $^{12}$ in support of REDD+ (Johns et al., 2008; Niles et al., 2009; Park et al., 2013). ${ }^{13}$ Norway was and still is by far the main donor to REDD+ even though other donor countries soon followed with financial commitments. At COP-14 in 2008 Germany pledged USD 52 million to REDD+ through its International Climate Initiative; at COP-15 in 2009 the US announced a commitment of USD 1 billion to REDD+; and in 2010 Australia followed with commitments of in total USD 931 million (Park et al., 2013). Another commitment that supported the REDD+ agreement in Bali itself was the announcement of the World Bank of a Forest Carbon Partnership Facility (FCPF), which would provide financial support to countries to make them "ready" for REDD+. ${ }^{14}$ Despite the fact that the launch was accompanied by loud protests from a large group of NGOs and social movements that opposed the involvement of the World Bank in REDD+, the FCPF policy of providing relatively small "Readiness Grants" to several dozens of countries ${ }^{15}$ secured broad support for REDD+ amongst those countries (Wertz-Kanounnikoff, 2007; den Besten et al., 2014).

The Bali decisions triggered a flurry of negotiations, funding commitments and demonstration activities related to REDD+ (Johns et al., 2008; Wertz-Kanounnikoff et al., 2008; Streck et al., 2009b). In May 2009, there were already 44 REDD+ demonstration activities and 65 REDD+ Readiness activities (Wertz-Kanounnikoff et al., 2008). Two influential British reports added to the REDD+ boost: another report by Professor Nicholas Stern on the key elements of a global climate change agreement, which dedicated a full chapter to financing emission reductions from deforestation (Stern, 2008); and the Eliasch review, Climate Change: Financing Global Forests, prepared for the UK prime minister in 2008, which concluded amongst other things that the long-term net benefits of halving deforestation could amount to USD 3.7 trillion (Eliasch, 2008; Lederer, 2012). Both reports contain a strong plea for the 
inclusion of forests in global carbon markets, with Eliasch claiming that it would reduce the overall costs of climate mitigation by 50 percent by 2020 and by up to 40 percent by 2050 (Eliasch, 2008). Literature from the period 2007-2009 shows a strong confidence that REDD+ would be part of an ambitious post-Kyoto climate agreement, and North American and European scholars especially expressed strong hopes that REDD+ would be financed through mandatory carbon markets, which were expected to receive a significant financial boost from the ambitious post-2012 targets the 2009 Copenhagen Climate COP was supposed to agree upon (Skutsch et al., 2007; Angelsen, 2008b; Johns et al., 2008; Streck et al., 2009b).

However, while negotiations on REDD+ itself progressed relatively smoothly in 2008 and even 2009 (Streck et al., 2009b), the overall climate negotiations soon became impossible to manage, if only because countries submitted more than 1000 pages of formal text proposals, which ended up in no fewer than 200 pages of official negotiation text to be resolved by December 2009 (Kulovesi and Gutierrez, 2009). Despite ten official negotiation sessions, by mid-2009 it was clear that it would be almost impossible to reach a comprehensive agreement at COP-15 in December 2009 in Copenhagen (Kulovesi and Gutierrez, 2009; Massai, 2010). After two weeks of intense discussions the negotiations collapsed dramatically at the final plenary session. The Copenhagen Accord, which had been the result of informal negotiations between US president Barack Obama and a select group of major emitting countries, and which included clear support for REDD+, was not adopted in the COP plenary owing to opposition by some of the countries that had not participated in the informal talks through which this accord was elaborated (Massai, 2010; Lesniewska, 2010).

\subsection{REDD+ ON THE ROAD TO PARIS}

The effects of the global economic crisis since 2008, which led to reduced emissions and thus reduced demand for carbon offsets in general, and the failure of the US government itself to agree on a clear climate policy had profound impacts on global carbon markets, where prices collapsed significantly (Peters-Stanley et al., 2011). While the UNFCCC process was still determining whether or not any future mandatory carbon market would include REDD+ offsets, the voluntary carbon market had already established REDD+ offsets. Forest carbon offset projects were relatively popular on voluntary carbon offset markets, and about 79 REDD+ Readiness activities and 100 REDD+ 
demonstration activities had been established by October 2009 (Cerbu et al., 2011; see also section 5.4). However, especially within the EU, the crisis on the carbon offset market added to existing concerns that the large quantity of carbon offset credits that could potentially be generated by reduced deforestation would flood its internal market, thus suppressing carbon prices even further (Bozmoski and Hepburn, 2009; Karsenty, 2012). This convinced the EU to continue to exclude forest carbon offsets from its internal Emissions Trading System (ETS) (Stephan and Paterson, 2012). ${ }^{16}$ As the ETS represented the cornerstone of the global carbon market, hopes that REDD+ would soon be financed through carbon markets started to fade away (Newell, 2012). With the FCPF especially continuing to finance national REDD+ Readiness activities that were strongly oriented toward a potential sale of forest carbon offset credits in a future carbon market, some negotiators started to ask "Ready for what?" (interview 22, September 2012). ${ }^{17}$

However, REDD+ was not dead yet. While expectations were initially low (Allan and Dauvergne, 2013), the 2010 COP took place in Cancun, Mexico, a forest-rich country that had an existing, reasonably wellfunctioning payments for environmental services (PES) mechanism. According to some interviewees, the president of Mexico decided to turn REDD+ into one of the priorities for the Cancun COP (interview 31, December 2012). REDD+ was seen as "low-hanging fruit" insofar as it was relatively less controversial than many other aspects of the post-2012 agreement (interview 33, December 2012; interview 40, December 2012). In a conference marked by strategic chairmanship, the COP adopted a compromise outcome that included an elaborate decision on REDD+. ${ }^{18}$ Noteworthy is that most negotiations took place in an informal setting, the so-called white room. Bolivia, which by then had developed a strong position against REDD+, carbon markets and any climate agreement that was insufficient to limit global warming to less than 1.5 degrees, had decided not to participate in these informal talks, as it considered this process undemocratic. When the outcomes of the white room were to be presented to the plenary of the Ad Hoc Working Group on Long-Term Cooperative Action (AWG LCA), Bolivia wanted to protest, but its lead spokesperson, Pablo Solon, was called away for a bilateral meeting with the COP president just before the working group plenary started. When he realized that the meeting had started he tried to rush back, but the room was overcrowded and guards tried to stop him from entering the room. His co-negotiator tried to protest against the adoption of the results of the informal white room negotiations during the official meeting, but she was ignored, and the results of the white room were adopted and forwarded to the plenary. At the plenary Bolivia 
protested again, but was overruled, because it was isolated in its protest at that time (interview 60, June 2014; interview 62, May 2015). In the end, the Cancun agreement was adopted with a footnote that takes note of the objections of Bolivia.

The REDD+ decision encourages developing countries to address forest loss and requests them to develop a national strategy or action plan, a national forest reference emission level and/or forest reference level, a national forest monitoring system and a system for providing information on how the relevant safeguards are being addressed. While placing these recommendations "in the context of the provision of adequate and predictable support, including financial resources" the decision itself is vague on where such support should come from. Rather, it requests the AWG LCA to "explore financing options."19

The decision determines that REDD+ should be implemented in three phases. The first phase is to develop national strategies or action plans; the second phase is to implement them; and the third phase is to evolve these implementation efforts "into results-based actions that should be fully measured, reported and verified." ${ }^{20}$ The decision also includes an elaborate appendix with 11 guidelines and seven safeguards, including safeguards that address biodiversity and respect for the knowledge and rights of Indigenous Peoples and local communities. Lastly, the COP requested the SBSTA to elaborate a work program on a number of outstanding matters, including identifying drivers of forest loss, establishing adequate reference levels and forest monitoring systems and developing modalities for monitoring, reporting and verification (MRV) of forest-related emissions and removals.

In the subsequent years, the AWG LCA and the SBSTA continued to work on their respective mandates related to REDD+. Little progress was made at COP-17 in 2011 in Durban or COP-18 in Doha, which focused on the controversial issue of financing sources for REDD+ (Newell, 2012; Allan and Dauvergne, 2013). However, at COP-20 in Warsaw in 2013 both processes succeeded in producing COP decisions. These compromise agreements were non-specific. The drivers of forest loss, for example, were addressed through a decision that is not even a page long and that mainly notes the "complexity of the problem." 21 The decision on reference levels leaves it up to countries themselves to develop the reference level they consider appropriate, and whether they would like that reference level to be technically assessed in the context of resultsbased payments. ${ }^{22}$

As analyzed in Chapter 6, the non-specificity of these decisions seriously compromises the effectiveness of REDD+ (see also Humphreys, 2008). The negotiations on reference levels for REDD+ took place 
parallel to complex negotiations on reference levels for LULUCF in the Ad Hoc Working Group on the Kyoto Protocol, and the LULUCF negotiations regularly influenced the REDD+ negotiations, leading to a situation in which both the industrialized countries that were party to the Kyoto Protocol and developing countries had a strong interest in flexible approaches to reference levels for the forest sector, despite the fact that such flexible approaches would compromise the environmental integrity of the climate regime (Fry, 2011).

As the heart of the REDD+ mechanism is formed by results-based payments, the non-specificity of the decision on finance ${ }^{23}$ has even more serious consequences for the effectiveness of the mechanism. In fact, the 2010 Cancun agreement on REDD+ explicitly states that REDD+ activities are contingent on "adequate and predictable support," 24 but no firm agreement has been reached as yet that would ensure the predictability of support, or its adequacy (McDermott, 2014). The 2013 decision merely requests various potential funding sources to provide finance for REDD+ in compliance with previous UNFCCC decisions, and limits itself to establishing an information hub on the web platform of the UNFCCC website as far as concrete actions are concerned. Moreover, even that action is subject to the availability of financial resources. ${ }^{25}$

The question whether REDD+ actions will be financed primarily through public funds or through forest carbon offset markets has been and continues to be one of the most controversial questions in the negotiations. A 2012 report commissioned by the EU outlines four major policy options: (1) a global market-based mechanism, (2) a project-based approach, (3) a centralized funding scheme and (4) an international fund to invest in policies and programs (Karsenty, 2012). These options are described in Table 1.1.

The above categories are not rigid or mutually exclusive. In fact, many countries have allowed REDD+ projects to be financed through the voluntary carbon offset market while they are in the process of developing a national REDD+ program to be financed through either public funds or potential carbon markets in the future, an approach that is called the "nested approach" (Karsenty, 2012; see also section 7.4).

The financing options for REDD+ raise the question of whether REDD+ should be considered a market-based or a non-market-based approach. It is often suggested that REDD+ will only be market-based if it is primarily financed through carbon markets, but one could argue that results-based payments are based on the concept of markets for environmental services, which reflects an inherently market-based, or at least market-oriented, approach. Since 2010 this has been the position of the Bolivian government, which has frequently opposed REDD+ as a 
Table 1.1 Financing options for REDD+

\begin{tabular}{|c|c|}
\hline Financing option & Description \\
\hline $\begin{array}{l}\text { Global market-based } \\
\text { mechanism }\end{array}$ & $\begin{array}{l}\text { REDD+ countries are awarded "carbon assets" for } \\
\text { reductions in emissions from REDD+ activities below a } \\
\text { national baseline. Industrial countries (and/or companies) } \\
\text { can purchase these credits, possibly to offset their own } \\
\text { industrial emissions and meet compliance targets for GHG } \\
\text { reductions. }\end{array}$ \\
\hline $\begin{array}{l}\text { Project-based } \\
\text { approach }\end{array}$ & $\begin{array}{l}\text { Certified emission reductions from projects are traded on a } \\
\text { global market. This differs from the first approach in that } \\
\text { projects can be credited directly, rather than accounting for } \\
\text { emission reductions on a national level. }\end{array}$ \\
\hline $\begin{array}{l}\text { Centralized funding } \\
\text { scheme }\end{array}$ & $\begin{array}{l}\text { An international fund rewards governments or programs for } \\
\text { changes in deforestation rates, or reduced emissions from } \\
\text { REDD+ activities, below a national baseline. }\end{array}$ \\
\hline International fund & $\begin{array}{l}\text { An international fund is used to finance investment in } \\
\text { sectoral and extra-sectoral polices and measures. } \\
\text { Performance is assessed against policy implementation } \\
\text { indicators rather than through changes in deforestation rates } \\
\text { against a baseline. }\end{array}$ \\
\hline
\end{tabular}

Source: Prepared on the basis of Karsenty (2012: 31).

market-based mechanism and proposed a Joint Mitigation and Adaptation Mechanism as a non-market-based alternative instead. ${ }^{26}$

While REDD+ itself can be classified as a PES system, not all countries have established their own national PES mechanisms to further share the payments the government receives, or expects to receive, with forest owners and other actors on the ground (see section 5.2). The nature of REDD+ is further complicated, as there has been a tendency to reclassify both voluntary forest carbon offset projects and national government policies and programs that were established prior to the regime's adoption as REDD+ (see section 7.4).

The Stern (2006) and Eliasch (2008) reports strongly promoted mandatory carbon markets as the major funding source for REDD+, in the expectation that they would generate up to USD 33 billion per year (Eliasch, 2008: 75), but in reality only a fraction of REDD+ finance has been generated through carbon markets (see section 5.4). Industrialized countries claim to have contributed significantly to public finance for REDD+, but discussions in the REDD+ Partnership about the Voluntary REDD+ Database revealed that there is a significant gap between the USD 7.59 billion in funding they claim to have contributed to REDD+ ${ }^{27}$ 
and the USD 4.68 billion recipient countries claim these donors contributed to REDD+ up to $2015 .{ }^{28}$ This is because, inter alia, industrialized countries redefine existing financial support for forest conservation or even just forest cover monitoring as REDD+ support (interview 47, June 2013). As a result, countries like India that do not have a formal REDD+ program are listed in the database as significant recipients of REDD+ support. ${ }^{29}$ Table 1.2 describes some of the differences between REDD+ support reported by donor countries and recipient countries.

\section{Table 1.2 REDD+ support according to donor and recipient countries}

\begin{tabular}{lll}
\hline $\begin{array}{l}\text { Countries that received more } \\
\text { than USD } 100 \text { million in } \\
\begin{array}{l}\text { REDD+ support according to } \\
\text { REDD+ donor countries }\end{array}\end{array}$ & $\begin{array}{l}\text { REDD+ support } \\
\text { received according to } \\
\text { donor countries } \\
\text { (USD million) }\end{array}$ & $\begin{array}{l}\text { REDD+ support } \\
\text { received according to } \\
\text { recipient country itself } \\
\text { (USD million) }\end{array}$ \\
\hline $\begin{array}{l}\text { Brazil } \\
\text { India }\end{array}$ & $\begin{array}{l}\text { (U86.74 } \\
\text { Indonesia }\end{array}$ & 862.33 \\
China & 710.66 & 0 \\
Guyana & 524.36 & 189.20 \\
Mexico & 268.33 & 61.34 \\
Democratic Republic of the & 212.43 & 9.92 \\
Congo & 210.16 & 70.98 \\
Tanzania & 158.92 & 54.60 \\
Laos & 136.71 & not reported \\
Philippines & 111.87 & 31 \\
Peru & 111.30 & not reported \\
Vietnam & 107.15 & not reported \\
Cameroon & 100.91 & 36.32 \\
\hline
\end{tabular}

Source: Voluntary REDD+ Database. See http://www.fao.org/forestry/vrd/data/by/ recipients and http://www.fao.org/forestry/vrd/data/by/funders (last visited December 21, 2016).

While the negotiations on many other climate-related issues did not produce any draft resolutions before the Paris COP in December 2015, the final meeting of the subsidiary bodies in June 2015 agreed on the last outstanding issues regarding the REDD+ regime. This concerned further guidance on safeguard information systems, alternative policy approaches such as joint mitigation and adaptation approaches, and non-carbon 
benefits. $^{30}$ This did not automatically mean that REDD+ would be included in the Paris Agreement. In fact, the paragraph referring to the REDD+ regime was subject to intense negotiations until the last moment in Paris itself. It was primarily Panama, represented by the former negotiator for Papua New Guinea, which strongly pushed for the inclusion of the following reference to the REDD+ regime:

Parties are encouraged to take action to implement and support, including through results-based payments, the existing framework as set out in related guidance and decisions already agreed under the Convention for: policy approaches and positive incentives for activities relating to reducing emissions from deforestation and forest degradation, and the role of conservation, sustainable management of forests and enhancement of forest carbon stocks in developing countries; and alternative policy approaches, such as joint mitigation and adaptation approaches for the integral and sustainable management of forests, while reaffirming the importance of incentivizing, as appropriate, non-carbon benefits associated with such approaches. ${ }^{31}$

As a compromise, the final article only provides a generic description of REDD+ without clearly establishing a REDD+ mechanism or even using the abbreviation REDD+, which featured in earlier drafts. ${ }^{32}$ It is also worth noting that the description of the REDD+ regime is accompanied by a description of alternative policy approaches to conserve forests, including joint mitigation and adaptation approaches for the integral and sustainable management of forests, thus formally providing equal status to REDD+ and its main alternative, the joint mitigation and adaptation approach.

\subsection{CONCLUSIONS}

This chapter has provided an introduction to global deforestation problems and why there is a need to address them through an environmentally effective, economically efficient and socially equitable international regime. By the time the governments decided to initiate negotiations on a subregime to reduce emissions from deforestation and forest degradation under the climate regime, there were already some 25 existing international regimes addressing deforestation, so it is questionable whether the new regime was really needed. The main question that will be addressed in this book is: "Which actors have been instrumental in shaping REDD+ policies and policy responses, what are their motivations and how do they use their agency to pursue their interests?" 
The chapter has provided an introduction to the role of agents in international regime development. Whether a certain actor is an agent behind a specific regime can be indicated by the legitimacy and authority of that actor, its success in pursuing its objectives, and whether it is seen as an agent by other actors in the relevant regime. The chapter also highlighted why it is important to analyze the motivations and strategies of agents in Earth System Governance. Existing regime development theories can be distinguished in power-based theories, which assume that a regime will be shaped to serve the interests of the most dominant actor, interest-based theories, which highlight the importance of economic interests in motivating actors to shape a certain regime, and knowledgebased theories, which assume that actors will shape a regime according to a logic of appropriateness. This book will analyze to what extent these theories are applicable to the motivations of the main agents behind the REDD+ regime and the strategies they used to pursue the regime. Thus it will analyze to what extent the flaws and gaps in the current REDD+ regime are the result of the power, economic interests and/or ideologies of the agents that shaped the regime, and the balance between the different agents.

This introductory chapter subsequently described the development of REDD+ as a subsystem under the global climate regime. It has taken a legal approach, analyzing the official positions of countries and how they resulted in a legal agreement around a result-based mechanism to pay for reduced deforestation and forest degradation, conservation, sustainable forest development and enhanced carbon sequestration. It analyzes how the REDD+ proposal was originally proposed by PNG on behalf of the CfRN, but that it received significant political impetus owing to the financial commitment by Norway to provide up to USD 3 billion funding for REDD+ at the COP where the decision to develop the regime was taken. Parties to the UNFCCC subsequently took more than eight years to elaborate the regime, which was finally incorporated in the 2015 Paris Agreement. However, while the final regime that was established presumes it will pay countries for the environmental services of reducing forest loss, there is a legal ambiguity in the UNFCCC regime and the 2015 Paris Agreement about whether such payments for reduced forest loss should be financed through public funds provided by industrialized countries, or through markets in forest carbon offsets. The consequences of this ambiguity are that there is uncertainty about the future of the REDD+ regime in general.

After this introduction about the legal status of the REDD+ regime, the following chapters will address REDD+ from an international political perspective. Chapter 2 will consider some of the main theories about 
international regime development and the role and strategies of agents in the elaboration of new international regimes. Chapter 3 and 4 will subsequently address the question of which actors have promoted the inclusion of REDD+ as a forest policy regime within the climate change policy regime, and how they used their agency to pursue their underlying interests and ideologies. Chapter 5 will discuss the assumptions of scholars and key actors in the REDD+ regime about the environmental effectiveness, economic efficiency and social equity of this new regime. Chapters 6, 7 and 8 will subsequently analyze how these assumptions about the effectiveness, efficiency and equity have worked out in reality, taking into account the REDD+ regime that was incorporated in the 2015 Paris Agreement.

Chapter 9 brings together the main conclusions of the previous chapters. It summarizes some of the positive and negative aspects of the REDD+ regime, and analyzes to what extent the REDD+ regime has been developed to serve the interests of certain actors that were able to act as intermediaries in REDD+ policies and projects rather than the rights and needs of Indigenous Peoples and other forest-dependent rightsholder groups. It provides a number of suggestions for more effective and equitable participation of the assumed beneficiaries of REDD+. It also analyzes how a more balanced agency by rightsholders, developing countries and industrialized countries in international sustainable development policymaking could be promoted and whether there are alternative options for more effective, efficient and equitable international regimes to reduce deforestation and forest degradation.

\section{NOTES}

1. The project cycle for LULUCF and other projects that are allowed in the CDM entails the following: The project needs to be described in a project design document which is validated by an accredited operational entity against the validation requirements that have been adopted by the parties to the Kyoto Protocol. Subsequently the project is registered by the executive board of the CDM, which also decides on the baseline and monitoring methodologies to be used. Once the project is in its implementation stage a different operational entity verifies based on the monitoring reports by the project participants how much carbon sequestration has taken place. This is thereafter certified by the verifying entity, which certifies this amount and requests the executive board to issue the corresponding amount of carbon credits (Graichen, 2005).

2. Two different types of temporary credits were created for afforestation and reforestation projects: temporary certified emission reductions (tCERs), which expire every five years, and long-term certified emission reductions (1CERs) which expire at the end of the crediting period of the project for which they were issued, or earlier if the carbon sequestered is emitted before the end of the project (Graichen, 2005; Boyd et al., 2008; Streck et al., 2009b). 
3. FCCC/CP/2001/13/Add.2, Decision 17/CP.7, Modalities and Procedures for a Clean Development Mechanism. United Nations. See https://unfccc.int/files/meetings/workshops/ other_meetings/application/pdf/17cp7.pdf (last visited December 23, 2016).

4. Directive 2004/101/EC of October 27, 2004 amending Directive 2003/87/EC establishing a scheme for greenhouse gas emission allowance trading within the Community, in respect of the Kyoto Protocol's project mechanisms, [2004] OJ L338/18.

5. See also http://medioambientesur.blogspot.com/2011/09/reducing-emissions-fromdeforestation.html (last visited March 15, 2015).

6. See for example the position of FoEI of 2008, http://www.REDD+-monitor.org/2008/10/ 29/foei-forests-are-more-than-carbon/, and its current position, http://www.foei.org/resources/ publications/publications-by-subject/forests-and-biodiversity-publications/the-great-REDD+gamble-2 (last visited May 28, 2015).

7. https://pwccc.wordpress.com/2010/04/24/peoples-agreement/ (last visited April 20, 2015).

8. See also http://medioambientesur.blogspot.com/2011/09/reducing-emissions-fromdeforestation.html (last visited March 15, 2015).

9. See also http://medioambientesur.blogspot.com/2011/09/reducing-emissions-fromdeforestation.html (last visited March 15, 2015).

10. Decision 1/CP.13 in FCCC/CP/2007/6/Add.1.

11. Decision $2 / \mathrm{CP} .13$ in FCCC/CP/2007/6/Add.1.

12. USD 2.7 billion is the amount according to the exchange rates in 2007 . It is worth noting the value of the Norwegian krone declined significantly in 2014 and 2015, and 15 billion krone would be worth only USD 1.7 billion in July 2016. See https://www.oanda.com/ currency/converter/ (last visited July 21, 2016). So the slow disbursement of funds has impacted the amount of funding available.

13. http://www.regjeringen.no/en/dep/md/Selected-topics/climate/the-government-of-norwaysinternational-/why-a-climate-and-forest-initiative.html?id=547202 (last visited May 28, 2015).

14. See https://www.forestcarbonpartnership.org (last visited May 28, 2015).

15. By 2015 no fewer than 47 countries had been selected to receive support from the FCPF, https://www.forestcarbonpartnership.org/REDD+-countries-1 (last visited May 28, 2015).

16. EC (2008) Addressing the challenges of deforestation and forest degradation to tackle climate change and biodiversity loss. Communication from the Commission to the European Parliament, the Council, the European Economic and Social Committee and the Committee of the Regions. Com(2008) 645/3. European Commission, Brussels.

17. Several countries also openly asked this question at the 11th meeting of the FCPF of March 28-30, 2012 in Asuncion, Paraguay (personal observation).

18. Decision 1/CP.16 in FCCC/CP/2010/7/Add.1.

19. Decision 1/CP.16 in FCCC/CP/2010/7/Add.1, Par. 71 and Par. 77.

20. Decision 1/CP.16 in FCCC/CP/2010/Add.1.

21. Decision 15/CP.19 in FCCC/CP/2013/10/Add.1.

22. Decision 13/CP.19 in FCCC/CP/2013/10/Add.1.

23. Decision 9/CP.19 in FCCC/CP/2013/10/Add.1.

24. Decision $1 / \mathrm{CP} .16$ in $\mathrm{FCCC} / \mathrm{CP} / 2010 /$ Add. 1.

25. Decision 9/CP.19 in FCCC/CP/2013/10/Add.1.

26. See https://unfccc.int/files/bodies/awg-lca/application/pdf/3_bolivia_ws_REDD+_bkk_ august_2012.pdf (last visited July 17, 2016).

27. http://www.fao.org/forestry/vrd/by/funders (last visited May 28, 2015).

28. http://www.fao.org/forestry/vrd/by/recipients (last visited May 28, 2015).

29. According to data provided by funders to the Voluntary REDD+ Database of May 28, 2015 India had received USD 722.95 million in REDD+ funding, while India itself reported zero support. See http://www.fao.org/forestry/vrd/data/by/funders (last visited May 28, 2015). According to the 2016 overview USD 76.18 million had been committed to India by four different donors, but nothing had been disbursed at that time. See Voluntary REDD+ Database, http://www.fao.org/forestry/vrd/download/en/ (last visited July 16, 2016). 
30. FCCC/SBSTA/2015/2/Add.1. See http://unfccc.int/resource/docs/2015/sbsta/eng/02a01.pdf (last visited July 7, 2016).

31. Article 5.2, Paris Agreement, see http://unfccc.int/files/essential_background/convention/ application/pdf/english_paris_agreement.pdf (last visited July 7, 2016).

32. For example, FCCC/ADP/2015/L.6. 